\title{
Qualidade de águas consumidas por alunos indígenas em escola rural de Barra do Bugres/MT
}

A água é essencial à vida, necessária para quase todas as atividades humanas, devem estar em qualidade adequada principalmente para a preparação de bebidas e alimentos. No entanto, em áreas rurais se recorre a águas subterrâneas retiradas de poços, que podem ter sua qualidade afetada por atividades agrícolas e a falta de saneamento. $O$ estudo teve por objetivo avaliar a qualidade da água de uma escola rural utilizada para abrigar estudantes das aldeias indígenas da região, por meio de variáveis físicas, químicas e microbiológicas de: $\mathrm{pH}$, condutividade elétrica, turbidez, oxigênio dissolvido, D.B.O, sólidos totais, nitrato, fosfato, sódio, potássio, cloretos, dureza, cálcio, magnésio e bicarbonatos; coliformes totais e coliformes termotolerantes avaliados durante quatro meses em dois pontos de coleta, Poço e Torneira. Os resultados obtidos demonstraram contaminação nas águas por coliformes totais e termotolerantes em ambos os pontos avaliados e variáveis físicas e químicas fora dos padrões recomendados pela portaria de Consolidação no 5 , de 28 de setembro de 2017, do Ministério da Saúde. O estudo demonstra a relevância do monitoramento da qualidade da água como indicador de fontes de transmissão de doenças hídricas, ressaltando a importância de manter o acompanhamento das variáveis estudadas e rotinas de higienização, a fim de oferecer condições adequadas aos estudantes.

\section{Quality of water consumed by indigenous students in rural school of Barra do Bugres/MT}

\begin{abstract}
Water is essential to life, necessary for all human activities, and it must have good quality for the beverage and food preparation. However, the water used in rural areas is from wells groundwater that may have its quality affected by agricultural activities and poor sanitation. The aim of this study was to evaluate the wate quality of a rural school used to house indigenous students in the region and it was done through physical, chemical and microbiological variables: $\mathrm{pH}$, electrica conductivity, turbidity, dissolved oxygen, B.O.D. (biochemical oxygen demand), total solids, nitrate, phosphate, sodium, potassium, chloride, hardness, calcium, magnesium, and bicarbonate; total and fecal coliforms. These variables were evaluated for four months at two collection points: a well and a tap. The results of both showed that there are contaminations in the water by total and fecal coliforms; in addition, the physicochemical variables are outside the established standards by government Consolidation Order $n=5$, September 28, 2017 of the Ministry of Health. The study demonstrates the importance of monitoring water quality as an indicator of sources of transmission of water diseases, emphasizing the importance of maintaining the monitoring of the studied variables and hygiene routines, in order to offer adequate conditions to students.
\end{abstract}

Keywords: Groundwater; Microbiology; Physicochemical Analysis.

Topic: Engenharia Sanitária

Reviewed anonymously in the process of blind peer.
Received: 09/05/2020

Approved: 06/06/2020
Carine Schmitt Gregolin Caloi (iD)

Universidade do Estado de Mato Grosso, Brasil

http://lattes.cnpq.br/3812958625271399

http://orcid.org/0000-0002-0349-3977

carine.schmitt@gmail.com

Edilaine Alvarenga Gonçalves (iD)

Universidade do Estado de Mato Grosso, Brasil

http://lattes.cnpq.br/1227194920449499

http://orcid.org/0000-0002-4442-1144

edilainealvarenga@hotmail.com

Ana Clara Brito de Figueiredo (iD)

Universidade do Estado de Mato Grosso, Brasil

http://lattes.cnpq.br/7293659424970993

http://orcid.org/0000-0001-8421-7386

anabritoo@hotmail.com

\section{Jéssica Ramos de Oliveira (iD) \\ Universidade do Estado de Mato Grosso, Brasil \\ http://lattes.cnpq.br/5961662650816768 \\ http://orcid.org/0000-0003-1450-3859 \\ jessica-r24@hotmail.com}

Adriane Silva Campos

Universidade do Estado de Mato Grosso, Brasil

http://lattes.cnpq.br/9240943105385513

adrianecampos17@outlook.com

Tadeu Miranda de Queiroz (it)

Universidade do Estado de Mato Grosso, Brasi

http://lattes.cnpq.br/2582121765769124

http://orcid.org/0000-0002-1959-7658

tdmqueioz@unemat.br

Referencing this:

CALOI, C. S. G.; GONÇALVES, E. A.; FIGUEIREDO, A. C. B.; OLIVEIRA, J. R.; CAMPOS, A. S.; QUEIROZ, T. M.. Qualidade de águas consumidas por alunos indígenas em escola rural de Barra do Bugres/MT. Revista Ibero Americana de Ciências Ambientais, v.11, n.4, p.169-179, 2020. DOI: http://doi.org/10.6008/CBPC2179-6858.2020.004.0015 


\section{INTRODUÇÃO}

A água é um fator indispensável para a vida, tendo diversas utilidades, mas o consumo humano é o principal deles. O Brasil é o país que apresenta em sua totalidade a maior disponibilidade de água no mundo, porém este recurso não está distribuído de forma uniforme e apropriada para o consumo humano (BRASIL, 2015). De acordo com a Portaria de Consolidação no 5 do Ministério da Saúde (BRASIL, 2017) a água ideal para consumo humano é a potável, ou seja, aquela que se enquadra nos parâmetros químicos, físicos e microbiológicos propostos e assim não oferece riscos à saúde e pode ser ingerida independente de sua origem.

Em meio ao perímetro urbano há existência de unidades que fornecem o abastecimento público de água, conforme padrões preestabelecidos por lei de potabilidade, entretanto com o aumento da população não há uma infraestrutura suficiente para atender tal demanda, assim, consequentemente uma parte da população não tem acesso a estes benefícios, acarretando na utilização de fontes alternativas de água, onde muitas vezes são impróprias para o consumo humano (BRASIL, 2015).

O cenário na zona rural se torna ainda mais grave, pois a população ali presente não é beneficiada com o fornecimento de água tratada, sendo necessário o uso de fontes alternativas para o consumo, cuja população geralmente não utiliza de métodos para purificação da mesma (QUEIROZ et al., 2018). A água é um importante meio para a propagação de doenças, pois suas características físico-químicas e microbiológicas podem ser alteradas constituindo fator de risco. Tais doenças podem inclusive provocar óbitos contribuindo para agravamento da mortalidade infantil, uma triste realidade brasileira. A contaminação microbiológica na água provocada pela bactéria E. coli pode ocasionar doenças como diarreia, rotavirose, hepatite e, principalmente, verminoses intestinais (BRASIL, 2015).

Crianças, idosos e indivíduos imunossuprimidos são os mais vulneráveis a doenças de origem hídricas (SILVA et al., 2018), desta forma a situação se agrava ainda mais nos quesitos das escolas rurais, pois nas escolas as os alunos deveriam encontrar um ambiente seguro, que não as expusessem a agentes contaminantes, haja vista que elas passam grande parte do dia na instituição consumindo água de forma direta e indiretamente. A Escola Agrícola Municipal Dep. Hitler Sansão, está localizada no município de Barra de Bugres, em Mato Grosso, em meio à extensa área de monocultivo de cana-de-açúcar. A escola encontrase desativada no momento, contudo durante o período de férias, a mesma é utilizada para abrigar e lecionar curso superior para estudantes das aldeias indígenas da região.

Sabendo que a escola em estudo abriga 120 indígenas, estudantes da Faculdade Intercultural da Universidade do Estado de Mato Grosso durante o determinado período presencial de seus estudos, visto que suas aulas são divididas em etapas presenciais e intermediárias (UNEMAT, 2018), faz-se necessário a realização de análises que comprovem a potabilidade da água na instituição, conforme determinado pela portaria vigente. Diante do exposto, o estudo teve como objetivo avaliar a qualidade da água da Escola Agrícola Municipal Dep. Hitler Sansão por meio das diretrizes da Portaria de Consolidação PRC no 5, de 28 de setembro de 2017, do Ministério da Saúde. 


\section{MATERIAIS E MÉTODOS}

\section{Área de estudo}

O estudo foi desenvolvido na Escola Agrícola Municipal Dep. Hitler Sansão, localizada na zona rural do município de Barra do Bugres/MT, fundada no ano de 1975. Durante o período de férias da Universidade do Estado de Mato Grosso Campus de Barra do Bugres é cedida para a Faculdade Intercultural Indígena, sendo utilizada como alojamento para os indígenas da região que estudam nos cursos de ensino superior de formação de professores.

O município de Barra do Bugres tem o seu desenvolvimento econômico através do rio Paraguai, considerado um importante curso da água, está diretamente ligado à monocultura da cana-de-açúcar, com mais de 37 mil hectares plantadas, que abastecem duas grandes usinas sucroalcooleiras da região, sendo uma destas situada próximo a escola, cerca de 900 m de distância.

O município é caracterizado por um clima tropical quente e sub-úmido, com precipitação média anual em torno de $1.800 \mathrm{~mm}$. De acordo com Martins et al. (2011), a região possui quatro períodos distintos, denominado período chuvoso, entre os meses de novembro a março, período de transição entre o período chuvoso e seco (transição 1), nos meses de abril e maio, período seco, que ocorre entre junho a agosto, e por fim o período de transição entre período seco e chuvoso (transição 2), nos meses de setembro e outubro.

\section{Coletas e procedimentos laboratoriais}

As coletas das amostras foram realizadas mensalmente, durante quatro meses, entre junho a setembro de 2018, englobando o período seco e o período de transição entre seca e chuva na região (MARTINS et al., 2011). Foram selecionados dois pontos de coleta, o poço (P) e a torneira do bebedouro (T), a fim de aferir possíveis alterações na qualidade da água em seu percurso de origem até o bebedouro.

As coletas foram realizadas no período matutino, em frascos de polietileno de $1 \mathrm{~L}$, ambientados com a água do local. Para as análises microbiológicas foi utilizado potes específicos de $100 \mathrm{~mL}$, previamente esterilizados. Os procedimentos para coleta seguiram as recomendações feitas pela CETESB (2009) e ANA (2011).

Em campo foi verificada a temperatura da água, através de um termômetro de mercúrio. No Laboratório de Qualidade de Água (LaQuA) da Universidade do Estado de Mato Grosso (UNEMAT), no Campus 'Deputado Estadual René Barbour' em Barra do Bugres/MT, determinou-se as seguintes variáveis físico-químicas: pH, através de ph metro (marca Marconi - modelo PA200); condutividade elétrica (CE) com uso de condutivímetro (marca Digimed - modelo DM-31), turbidez (Tu) através de turbidímetro (marca Hanna - modelo C102) pelo método Nefelométrico, oxigênio dissolvido (OD) com uso do equipamento oxímetro (marca Hanna - modelo HI9146), demanda bioquímica de oxigênio (DBO) pelo método de incubação 5 dias a 20ㅡ, sólidos totais (ST) pelo método gravimétrico, nitrato (N) e fosfato (P) pelo método espectrofotométrico, sódio ( $\mathrm{Na}$ ) e potássio (K), através da espectrofotometria de emissão em chama, cloretos $(\mathrm{Cl})$, dureza $(\mathrm{Du})$, cálcio $(\mathrm{Ca})$, magnésio $(\mathrm{Mg})$ e bicarbonatos $\left(\mathrm{HCO}_{3}-\right)$, por titulometria. As variáveis 
microbiológicas de coliformes totais (C.T.) e coliformes termotolerantes (C.F.), foram analisadas pelo método dos tubos múltiplos.

As análises físico-químicas seguiram as recomendações Standard Methods for the Examination of Water and Wastewater (APHA, 2005), enquanto as análises microbiológicas seguiram as indicações da Normativa 62 do Ministério da Agricultura, Pecuária e Abastecimento (MAPA, 2011).

\section{Análises estatísticas}

Os dados obtidos foram submetidos a análise estatística descritiva, através da obtenção da média, valores máximo e mínimo, desvio padrão e coeficiente de variação. Posteriormente a teste Scott-Knott a 5\% de significância sobre todos os resultados mensais obtidos, utilizando o software RStudio.

\section{RESULTADOS E DISCUSSÃO}

Os resultados das análises físico-químicas para a torneira $(T)$ e poço $(P)$ da Escola Agrícola estão apresentados na Tabela 1.

Tabela 1: Estatística descritiva das variáveis analisadas no Poço (P) e Torneira (T).

\begin{tabular}{|c|c|c|c|c|c|c|c|c|c|c|c|c|}
\hline \multicolumn{7}{|c|}{ Poço } & \multicolumn{6}{|c|}{ Torneira } \\
\hline Variáveis & Méd & Min & Max & D.P & C.V & SK (5\%) & Méd & Min & Max & D.P & C.V (\%) & SK (5\%) \\
\hline Temp $\left({ }^{\circ} \mathrm{C}\right)$ & 27,67 & 27,00 & 28,50 & 0,76 & 2,76 & $\mathrm{a}$ & 23,00 & 16,50 & 27,50 & 5,77 & 25,07 & $\mathrm{a}$ \\
\hline $\mathrm{pH}$ & 4,833 & 4,433 & 5,167 & 0,372 & 7,70 & $a$ & 5,183 & 4,333 & 6,233 & 0,784 & 15,13 & $a$ \\
\hline $\mathrm{CE}(\mu \mathrm{S} \mathrm{cm}-1)$ & 57,125 & 45,167 & 64,970 & 8,435 & 14,77 & $a$ & 54,576 & 53,187 & 56,503 & 1,588 & 2,91 & $a$ \\
\hline Turb (UNT) & 9,153 & 0,000 & 17,767 & 8,748 & 95,57 & $a$ & 9,121 & 0,00 & 21,750 & 10,914 & 119,66 & $a$ \\
\hline $\mathrm{OD}(\mathrm{mg} \mathrm{L}-1)$ & 3,927 & 3,083 & 4,667 & 0,668 & 17,01 & $a$ & 4,145 & 3,390 & 4,407 & 0,503 & 12,14 & $a$ \\
\hline S.T. (mg L) & 52,00 & 39,00 & 66,00 & 12,62 & 24,27 & $a$ & 35,75 & 5,00 & 55,00 & 21,50 & 60,14 & a \\
\hline $\mathrm{N}$ - Total (mg L) & 0,575 & 0,545 & 0,612 & 0,029 & 5,00 & $a$ & 0,581 & 0,534 & 0,619 & 0,044 & 7,57 & $a$ \\
\hline P-Total (mg L) & 0,147 & 0,121 & 0,173 & 0,022 & 15,02 & $a$ & 0,149 & 0,128 & 0,175 & 0,020 & 13,13 & $a$ \\
\hline $\mathrm{Na}(\mathrm{mg} \mathrm{L})$ & 0,803 & 0,103 & 1,334 & 0,573 & 71,38 & $a$ & 0,732 & 0,085 & 1,202 & 0,490 & 67,00 & $a$ \\
\hline $\mathrm{K}$ & 2,159 & 1,169 & 2,763 & 0,694 & 32,15 & $a$ & 2,052 & 1,036 & 2,467 & 0,686 & 33,43 & $a$ \\
\hline $\mathrm{Cl}$ & 3,435 & 2,617 & 3,926 & 0,626 & 18,24 & $\mathrm{a}$ & 3,490 & 3,272 & 3,926 & 0,308 & 8,84 & $\mathrm{a}$ \\
\hline Dureza & 66,374 & 18,962 & 105,658 & 39,21 & 59,07 & $a$ & 89,539 & 21,332 & 119,746 & 45,945 & 51,31 & a \\
\hline $\mathrm{Ca}$ & 20,629 & 4,750 & 54,410 & 22,757 & 110,31 & $a$ & 13,472 & 6,966 & 18,050 & 5,787 & 42,96 & $a$ \\
\hline $\mathrm{Mg}$ & 8,515 & 1,729 & 18,680 & 8,967 & 105,30 & $a$ & 11,840 & 0,960 & 18,213 & 9,468 & 79,97 & $a$ \\
\hline $\mathrm{HCO}_{3}$ & 3,712 & 2,012 & 8,050 & 2,914 & 78,49 & $a$ & 3,209 & 2,012 & 6,037 & 1,919 & 59,81 & $a$ \\
\hline Alcalinidade & 4,310 & 3,354 & 5,550 & 1,125 & 26,11 & $a$ & 3,092 & 2,012 & 4,025 & 1,014 & 32,80 & $a$ \\
\hline
\end{tabular}

Os resultados obtidos para temperatura no Poço nos períodos avaliados chegaram à máxima de $28,5^{\circ} \mathrm{C}$, com média de $27,67^{\circ} \mathrm{C}$, com coeficiente de variação baixo, 2,76\%. Já na Torneira a máxima foi de $27,5^{\circ} \mathrm{C}$ com média de $23^{\circ} \mathrm{C}$, e um coeficiente de variação de $25,07 \%$. As coletas ocorreram no período da manhã, em torno das 6h30min e 7h00min. Não há referências sobre os valores máximos e mínimos permitidos de temperatura da água para consumo humano, a CETESB (2009) apenas faz uma menção que a temperatura esteja entre 0 e $30^{\circ} \mathrm{C}$, e podem sofrer influências de vários fatores como, altitude, latitude, estação do ano, períodos de chuva e seca, no entanto, águas com temperaturas superiores a $27,0^{\circ} \mathrm{C}$ são desagradáveis ao paladar. Desta forma, a temperatura mínima registrada para torneira $\left(16,5^{\circ} \mathrm{C}\right)$ está relacionada à queda na temperatura externa, em que ocorreu um dia de frio durante as coletas. Conforme Queiroz et al. (2018) deve-se ter maior atenção com águas mais quentes, pois podem apresentar riscos à saúde, devido à proliferação de organismos patogênicos, tornando a água uma forma muito comum de 
contaminação microbiológica, em contrapartida os consumidores costumam rejeitá-la, preferindo consumir águas em temperaturas mais baixas.

Quanto aos valores observados para condutividade elétrica, a Portaria de Consolidação n $05 / 17$ do MS não estabelece valores de referência, no entanto, as águas naturais apresentam teores de condutividade na faixa de 10 a $100 \mu \mathrm{S} / \mathrm{cm}^{-1}$. Nas amostras obteve-se o valor máximo de $65 \mu \mathrm{S} / \mathrm{cm}^{-1}$ para Poço e $56,5 \mu \mathrm{S} / \mathrm{cm}^{-}$ ${ }^{1}$ para Torneira, demonstrando-se dentro da normalidade, e suas médias não se diferiram pelo Teste ScottKnott 5\%. Os pontos Poço e Torneira apresentaram uma quantidade de sólidos totais máximos de 59 e 42 mg. $\mathrm{L}^{-1}$, respectivamente, valores muito abaixo do estabelecido pela Portaria de Consolidação $n^{\circ} 05 / 17$ do MS, em que o valor máximo permitido é de $1000 \mathrm{mg} \cdot \mathrm{L}^{-1}$, indicando a boa qualidade destas águas e a adequação desta variável para o consumo humano na Escola Agrícola.

Santos et al. (2013) afirmam que a condutividade elétrica não representa nenhum risco à saúde humana, contudo, é possível inferir a concentração de sólidos totais por meio da $\mathrm{CE}$, e em presença acima do permitido, tornam a água com sabor desagradável, e acúmulo de sais na corrente sanguínea, podendo causar problemas relacionados a cálculos renais, o que não foi observado nos períodos analisados. Assim como os resultados encontrados para sólidos totais corroboram para um baixo risco de danos nocivos à saúde humana.

Para o pH, a Portaria de Consolidação n $05 / 17$ do MS estabelece a faixa de 6 e 9,5, no entanto, as amostras coletadas nesse estudo se apresentaram com características mais ácidas para o ponto Poço (mínima de 4,4 e máxima de 5,2), sendo o ponto Torneira apresentou mínimo de 4,3 e máxima de 6,2, com coeficiente de variação maior observado na Torneira do que no Poço, entretanto as médias não se diferiram entre os pontos no teste aplicado, apresentando-se fora dos padrões de potabilidade propostos. Os baixos valores encontrados podem estar relacionados ao fato de a água não ser proveniente de abastecimento público, e sim de fontes subterrâneas, não possuindo nenhum tratamento.

Os resultados encontrados na Escola agrícola possuem semelhança com o observado por Scurachio et al. (2012), pH abaixo 6,0 apresenta risco de agressividade contra os materiais com que a água mantém contato, principalmente metálicos, como do bebedouro, reduzindo a vida útil e diluindo estes constituintes que corroboram com a diminuição da qualidade água, o que pode estar ocorrendo com a água da faculdade indígena, no entanto, pH ácido não causam malefícios a saúde.

Segundo Battalha et al. (1993) a presença da turbidez acima dos valores considerados ideais pelo padrão de potabilidade indica a presença de substâncias em suspensão, que podem ser resultantes de armazenamento incorreto da água. A Portaria de Consolidação no 05/17 do Ministério da Saúde define que a água para o consumo humano não ultrapasse cinco unidades nefelométricas de turbidez (UNT), os meses de agosto e setembro apresentaram resultados acima deste limite em ambos os pontos, a turbidez é indicativa da presença de sólidos dissolvidos em suspensão ou material em estado coloidal, porém podem ter relação com a elevada concentração de ferro proveniente da má condição da bomba do poço, (encanamentos enferrujados) ou da própria natureza das rochas. Sendo assim, a turbidez elevada, observada em ambos os pontos, pode ser derivado, tanto do revolvimento de sedimentos no fundo do reservatório de 
água, quanto de encanamentos enferrujados, que podem comprometer a qualidade sensorial da água, refletindo em risco à saúde do consumidor, pois a mesma não passa por processo de cloração, o que propicia, conforme Campos et al. (2003), o desenvolvimento de microrganismos.

A Resolução 357/2005 do Conselho Nacional do Meio Ambiente - CONAMA, estabelece para águas de Classe 1, consideradas para abastecimento e consumo humano após tratamento, a quantidade de oxigênio dissolvido, não seja inferior a $6 \mathrm{mg} \cdot \mathrm{L}^{-1}$, enquanto que para demanda bioquímica de oxigênio, em 5 dias a $20^{\circ} \mathrm{C}$, o valor seja de até $3 \mathrm{mg} \cdot \mathrm{L}^{-1}$. Conforme Brasil (2014), o OD é expressamente importante para avaliação da qualidade da água, estando associado a processos físico-químicos e microbiológicos da mesma. As amostras analisadas apresentaram valores para OD no ponto $P$ entre 3,1 e $4,7 \mathrm{mg} \cdot \mathrm{L}^{-1}$, com coeficiente de variação de $17,01 \%$ e, no ponto $\mathrm{T}$, variando de 4,1 e $4,4 \mathrm{mg} \cdot \mathrm{L}^{-1}$, com coeficiente de variação de $12,14 \%$, estando ambos desconformes com os padrões estabelecidos, que podem estar relacionados ao tempo de armazenamento da água dentro dos reservatórios, diminuindo a quantidade de oxigênio presente na água, que está relacionado ao fluxo sazonal de uso da escola.

Conforme a CETESB (2009), o nitrato em excesso é altamente perigoso pela sua grande toxicidade, expondo recém-nascidos ao risco de cianometahemoglobinemia, também conhecida como a síndrome do bebê azul, em adultos estão ligadas ao câncer de mama e de estômago. Silva et al. (2018) também destaca que em zonas rurais é frequente o aumento da quantidade de nitrato na água devido a alguns fatores, como o excesso de uso de fertilizantes em lavouras, esgotos doméstico e preparação do solo para plantio.

A Portaria de Consolidação no 05/17 do MS, estabelece padrão de potabilidade da água para consumo humano do nitrato em valor máximo permitido $10 \mathrm{mg} \cdot \mathrm{L}^{-1}$. A CETESB (2009) considera como valor de prevenção de nitrato a concentração de $5 \mathrm{mg} \cdot \mathrm{L}^{-1}$. Os pontos analisados apresentam resultados em conformidade com os valores determinados, apresentando resultados extremamente inferiores para ambos pontos, sendo Poço com máximo $0,61 \mathrm{mg} \cdot \mathrm{L}^{-1}$ e Torneira com máximo de $0,62 \mathrm{mg} \cdot \mathrm{L}^{-1}$, com coeficiente de variação baixo para ambos, com Torneira com variações levemente superior, demonstrando que a água consumida na escola está dentro dos padrões estabelecidos, não oferecendo riscos à saúde humana. Contudo, a água da escola deve ser monitorada regularmente, haja vista a sua proximidade com áreas de cultivo de cana-de-açúcar, que podem contribuir para alteração da qualidade da mesma.

Em relação ao fosfato a Portaria do Ministério da Saúde, não estabelece valores máximos permitidos. Ambos os pontos obtiveram resultados semelhantes para fosfato, resultando em máxima de $0,173 \mathrm{mg} \cdot \mathrm{L}^{-1}$ para o Poço e 0,175 mg. $\mathrm{L}^{-1}$ para Torneira. A presença de fósforo na água, de acordo com a CETESB (2009), está relacionada a processos naturais (dissolução de rochas, carreamento do solo, decomposição de matéria orgânica, chuva) ou antropogênicos (lançamento de esgotos, detergentes, fertilizantes, pesticidas), podendo, desta forma, a presença do cultivo de cana-de-açúcar nas proximidades da escola ter influenciado nos resultados encontrados para fosfato.

Conforme Kemerich et al. (2013), altas concentrações de sódio na água, podem ser um fator limitante da mesma para a agricultura. A CETESB (2009) também pontua que os níveis de sódio em água potável devem ser menores de $20 \mathrm{mg} \cdot \mathrm{L}^{-1}$, que concentrações maiores podem apresentar gosto não agradável ao paladar 
humano. A Portaria de Consolidação n 05/17 do MS, define como valor máximo permitido para água potável, $200 \mathrm{mg} \cdot \mathrm{L}^{-1}$ de sódio. Os valores encontrados apresentaram média de $0,80 \mathrm{mg} \cdot \mathrm{L}^{-1}$ para o Poço e $0,73 \mathrm{mg} \cdot \mathrm{L}^{-1}$ para Torneira, com coeficiente de variação alto para ambos os pontos, demonstrando que as águas coletadas na Escola Agrícola estão dentro dos padrões permitidos para consumo humano, como também para o uso na agricultura apesar das altas variações entre as campanhas realizadas.

Os valores de potássio encontrados na água da Escola Agrícola variaram entre a mínima de 1,17 e máxima 2,76 mg.t-1 para o Poço, cujos valores próximos foram encontrados no ponto Torneira, que variou levemente a mais, entre 1,04 e $2,47 \mathrm{mg} \cdot \mathrm{L}^{-1}$. O Ministério da Saúde não estabelece valores máximos de potássio em águas de consumo humano, contudo a CETESB (2009) cita que águas naturais possuem valores menores que $10 \mathrm{mg} \cdot \mathrm{L}^{-1}$, valores na ordem de 100 a $25.000 \mathrm{mg} \cdot \mathrm{L}^{-1}$ podem apresentar águas com temperaturas elevadas e salmouras. Portanto, as águas da Escola Agrícola apresentaram-se dentro da normalidade para águas naturais.

Quanto a cloretos observou-se que ambos os pontos apresentaram valor máximo de 3,93 $\mathrm{mg} \cdot \mathrm{L}^{-1}$ durante o período avaliado. O Ministério da Saúde estabelece valor máximo permitido para água de consumo humano de $250 \mathrm{mg} \cdot \mathrm{L}^{-1}$, demonstrando que a água da Escola Agrícola está em conformidade com as normas exigidas. Queiroz et al. (2018), afirmam que valores altos de cloretos, não apresentam problemas a saúde, mas podem causar repulsa ao consumidor devido ao gosto salgado que a água pode apresentar, além de causar corrosão em tubulações de aço e alumínio, não sendo um problema encontrado nas análises da água da Escola, devido ao encanamento ser feito de material PVC, no entanto, como mencionado anteriormente, o bebedouro é metálico, merecendo devida atenção e manutenção periódica.

A dureza da água se deve ao fato da presença de compostos como o cálcio e magnésio, geralmente em forma de sulfatos, cloretos e carbonatos ( $\mathrm{KOCH}, 2017)$. A dureza é expressa em $\mathrm{mg} \cdot \mathrm{L}^{-1}$, correspondente a carbonato de cálcio $\left(\mathrm{CaCO}_{3)}\right.$. O Ministério da Saúde estabelece o padrão de dureza da água para consumo humano o limite de $500 \mathrm{mg} \cdot \mathrm{L}^{-1}$, as análises apresentaram valor mínimo de 18,96 mg. $\mathrm{L}^{-1}$ e máximo de 105,66 $\mathrm{mg} \cdot \mathrm{L}^{-1}$ de $\mathrm{CaCO}_{3}$ para o Poço, classificando como uma água mole a moderada, já o ponto Torneira apresentou mínima de 21,33 mg.L $\mathrm{L}^{-1}$ e $119,75 \mathrm{mg} \cdot \mathrm{L}^{-1}$ de $\mathrm{CaCO}_{3}$ de máxima, apresentando variação moderada, porém mais baixa e próximos da água do Poço, mas ambas as águas estão dentro dos padrões exigidos de potabilidade para consumo humano.

A variável de cálcio apresentou os médias de $20,63 \mathrm{mg} \mathrm{L}^{-1}$, com alto coeficiente de variação no Poço, registrando concentração máxima de $54,41 \mathrm{mg} \cdot \mathrm{L}^{-1}$ para os períodos avaliados. Para Torneira, houve uma variação moderada, com coeficiente de $42,96 \%$ e médias de $13,47 \mathrm{mg} \mathrm{L}^{-1}$. A variável de magnésio foi a que apresentou um coeficiente de variação elevado tanto para Poço (105,30\%), quanto Torneira (79,97\%) e médias de 8,52 $\mathrm{mg} \mathrm{L}^{-1}$ em Poço e 11,84 $\mathrm{mg} \mathrm{L}^{-1}$ em Torneira. Na literatura não são encontrados parâmetros que estabeleçam quantidade máxima de cálcio e magnésio na água de consumo humano, sendo dureza o indicador, e este, como já visto, está dentro dos padrões recomendados. Conforme Brasil (2014), águas mais duras apresentam maior quantidade de sais de cálcio e magnésio, os quais ocorrem de forma natural ou por elevadas quantidades de produtos químicos, durante o tratamento, causando incrustações nos 
encanamentos, que algumas vezes serve de proteção para evitar a corrosão, já para o ser humano em concentrações normais esses sais podem trazer benefícios a saúde, prevenindo doenças como a osteoporose e o crescimento saudável dos dentes.

A alcalinidade representa a capacidade da água de neutralizar ácidos, ou seja, substâncias que atuam como tamponamento, isso significa sua capacidade de resistir a mudanças do pH (SANTOS et al., 2013). Valores altos de alcalinidade podem ser associados a processos de decomposição da matéria orgânica e a alta elevação respiratória de microrganismos, que liberam gás carbônico nos cursos hídricos, que para consumo humano, em concentrações equilibradas, não causa danos à saúde, porém, altos níveis podem causar gosto desagradável (BRASIL, 2014). Em ambos os pontos as análises indicam desconformidade com os padrões estabelecidos, cuja Fundação Nacional de Saúde - FUNASA faz menção que estas apresentem valores de alcalinidade dentro dos limites de 30 a $500 \mathrm{mg} \cdot \mathrm{L}^{-1} \mathrm{de} \mathrm{CaCO}_{3}$, encontrando-se valores máximos para Poço e Torneira de $5,55 \mathrm{mg} \cdot \mathrm{L}^{-1}$ e 4,025 mg $\cdot \mathrm{L}^{-1}$, respectivamente. O coeficiente de variação de alcalinidade para ambos os pontos é moderado, sendo mais alto para Torneira (32,80\%). O Ministério da Saúde sugere que em águas com baixa alcalinidade pode-se corrigir a alcalinidade com uso de meio artificial, aplicando substâncias como cal ou barrilha, para alcance do padrão desejado (BRASIL, 2013), o que não ocorre nas águas da escola, pois a mesma não passa por processos de tratamento, sendo utilizada in natura.

De acordo com Marion et al. (2007) os íons carbonato e bicarbonato contribuem para a alcalinidade da água. Em ambos pontos avaliados o maior resultado foi de $8,05 \mathrm{mg} \cdot \mathrm{L}^{-1} \mathrm{em}$ Poço e $6,04 \mathrm{mg} \cdot \mathrm{L}^{-1}$ para Torneira. Para a Organização Mundial da Saúde, o controle das concentrações de bicarbonato, assim como de cálcio, carbonato e oxigênio são usados para medidas de controle de corrosão da água (WHO, 2011). Assim as águas analisadas possuem baixa concentração de bicarbonatos, contribuindo para o caráter mais ácido verificado nas amostras, que ocasionam prejuízos corrosivos nos equipamentos, como o bebedouro.

Ao aplicar o teste Scott-Knott a 5\% de confiabilidade, para verificar se há diferença entre as mesmas variáveis observadas para o Poço e Torneira considerando os valores apresentados durante as quatro campanhas amostrais, pode-se observar que estatisticamente as médias da mesma variável não apresentou diferenças entre Poço e Torneira, portanto estatisticamente as águas não sofrem grandes modificações em suas propriedades quanto saem do poço e passam pelo armazenamento até o consumo pelos alunos. No entanto, $50 \%$ das variáveis avaliadas possuem coeficiente de variação maior em Torneira com relação ao Poço, que podem estar sendo afetadas pelas condições e tempo de armazenamento desta água.

Quanto à qualidade microbiológica das águas avaliadas, a Portaria de Consolidação n 05/17 do MS estabelece que para água de consumo humano não deve haver a presença de coliformes totais, termotolerantes e Escherichia coli por $100 \mathrm{~mL}$ de amostras analisadas. São definidas no grupo dos coliformes termotolerantes, bactérias patogênicas que fermentam a lactose a temperatura de $44-45{ }^{\circ} \mathrm{C}$, sendo a principal a Escherichia coli (E. coli), única de origem fecal, estando presentes em fezes humanas e animais e algumas do gênero klebsiella, Enterobacter e Citrobacter (CETESB, 2009). Os resultados das análises microbiológicas para coliformes totais e termotolerantes, do tipo E. coli, estão apresentados no Quadro 1. 
Quadro 1: Resultados microbiológicos de coliformes totais e termotolerantes (E. coli) das águas da Escola Agrícola nos pontos Poço (P) e Torneira (T).

\begin{tabular}{|c|c|c|c|c|c|c|}
\hline \multicolumn{7}{|c|}{ Coliformes Totais (NMP.100 $\mathrm{ml}^{-1}$ ) } \\
\hline Ponto & Jun/18 & Jul/18 & Ago/18 & Set/18 & Parâmetro & Referência \\
\hline $\mathbf{P}$ & $<2,20$ & 2,20 & $<2,20$ & $<2,20$ & \multirow[b]{2}{*}{ Ausência em $100 \mathrm{~mL}$} & \multirow[b]{2}{*}{ Portaria de Consolidação n.o 05/17 do MS } \\
\hline $\mathbf{T}$ & $<2,20$ & 2,20 & $<2,20$ & $<2,20$ & & \\
\hline \multicolumn{7}{|c|}{ Coliformes Termotolerantes (NMP·100 $\mathrm{ml}^{-1}$ ) } \\
\hline Ponto & Jun/18 & Jul/18 & Ago/18 & Set/18 & Parâmetro & Referência \\
\hline $\mathbf{P}$ & 16,00 & $>16,00$ & 5,10 & 9,20 & \multirow[b]{2}{*}{ Ausência em 100 mL } & \multirow[b]{2}{*}{ Portaria de Consolidação n. 05/17 do MS } \\
\hline $\mathbf{T}$ & 5,10 & 16,00 & $<2,20$ & $<2,20$ & & \\
\hline
\end{tabular}

Os resultados apresentaram concentração elevada de coliformes totais durante os meses de coleta, sendo o mês de julho o que apresentou maior incidência em ambos pontos, que pode estar relacionado ao aumento de sólidos totais ocorridos no mês anterior, o qual foi verificado as máximas de $66 \mathrm{mg} \cdot \mathrm{L}^{-1}$ para Poço e $55 \mathrm{mg} \cdot \mathrm{L}^{-1}$ Torneira e como ficam armazenadas devido ao local não estar em uso, e aumento de sólidos podem estar refletindo no aumento nos resultados bacteriológicos. Silveira et al. (2011) ao avaliar a qualidade microbiológica de águas em escolas públicas, verificou que amostras de água não-potáveis foram encontradas nas que contavam com reservatório de água, e traz ainda que o resultado também foi verificado em duas regiões do Rio de Janeiro, onde eram maiores as contaminações em águas de reservatórios quanto comparados as que tinham abastecimento direto da rede pública. O mesmo pode estar ocorrendo nas águas da Escola Agrícola, visto que a mesma não realiza tratamento das águas do poço e também, o desconhecimento sobre a necessidade de higienização das caixas d'águas pode ter contribuído para a situação observada.

Em ambos os pontos e em todos os meses avaliados demonstram que a água não apresentou valores dentro do permitido pela norma vigente, podendo causar doenças de origem hídrica em seus consumidores. Grande parte das doenças transmitidas pela água estão associadas à contaminação fecal, sendo a bactéria $E$. coli o principal agente de propagação, portanto a mesma é utilizada como um indicador de contaminação fecal (BRASIL, 2014).

Os resultados indicaram que a água da escola possui baixa concentração de coliformes termotolerantes, do tipo $E$. coli, porém apenas o mês de julho apresentou concentração definida de 2,20 NMP. $100 \mathrm{ml}^{-1}$. As baixas concentrações encontradas são um indicativo da localização e construção adequada do poço, mas que podem ocorrer contaminações externas, ou infiltrações nas paredes do poço, assim como má higiene e conservação das tubulações e do reservatório de água. Portanto, os resultados representam um fator limitante da qualidade da água, pois está desconforme com a legislação vigente, não sendo, portanto, adequada ao consumo dos alunos indígenas, sem um prévio tratamento de desinfecção.

\section{CONCLUSÕES}

Os resultados indicaram que, no período analisado, a água utilizada na Escola Agrícola Dep. Hitler Sansão não está adequada para o consumo humano, em que os fatores limitantes de sua qualidade foram as variáveis de fosfato e turbidez, com valores acima do permitido, e as variáveis de pH e oxigênio dissolvido, com valores abaixo do indicado para o consumo humano. Foi verificada elevada contaminação 
microbiológica da água, com altas concentrações de coliformes totais, que tornam a água imprópria para o consumo humano.

O estudo comprova a importância do monitoramento da qualidade da água para consumo humano, principalmente em escolas, indicando as possíveis fontes de disseminação de doenças hídricas e sugere-se acompanhamentos periódicos, assim como realização de rotinas anuais de higienização dos reservatórios e bebedouros, além da verificação das condições estruturais do poço e tubulações com intuito de melhorar a qualidade das águas consumidas nesta escola.

AGRADECIMENTOS: Agradecemos a Fundação de Amparo à Pesquisa do Estado de Mato Grosso - FAPEMAT pela concessão de bolsas de mestrado, ao Conselho Nacional de Desenvolvimento Científico e Tecnológico (CNPq) pela concessão de bolsas de iniciação científica, e o apoio da Coordenação de Aperfeiçoamento de Pessoal de Nível Superior - Brasil (CAPES) - Código de Financiamento 01.

\section{REFERÊNCIAS}

ANA. Agência Nacional de Águas. Guia nacional de coleta e preservação de amostras: água, sedimento, comunidades aquáticas e efluentes líquidas. Brasília: ANA, 2011.

APHA. American Public Health Association. Standard Methods for the Examination of Water and Wastewater. 21 ed. Washington: APHA, 2005.

BATTALHA, B. L.; PARLATORE, A. C.. Controle da qualidade da água para consumo humano: bases conceituais $e$ operacionais. São Paulo: CETESB, 1993.

BRASIL. Ministério da Saúde. Fundação Nacional de Saúde. Manual de controle da qualidade da água para técnicos que trabalham em ETAS. Brasília: MS, 2014.

BRASIL. Ministério da Saúde. Fundação Nacional de Saúde. Manual Prático de Analise de Água. 4 ed. Brasília: MS, 2013.

BRASIL. Ministério da Saúde. Secretaria de Vigilância em Saúde. Análise de indicadores relacionados à água para consumo humano e doenças de veiculação hídrica no Brasil, ano 2013, utilizando a metodologia da matriz de indicadores da Organização Mundial da Saúde. Brasília: MS, 2015.

CAMPOS, J. A. D. B.; FARACHE FILHO, A.; FARIA, J. B.. Qualidade da água armazenada em reservatórios domiciliares: parâmetros físico-químicos e microbiológicos. Alimentos e Nutrição Araraquara, v.14, n.1, p.63-67, 2003.

CETESB. Companhia Ambiental do Estado de São Paulo. Significado ambiental e sanitário das variáveis de qualidade das águas e dos sedimentos e metodologias analíticas e de amostragem. Séries Relatórios. Qualidades das águas interiores do Estado de São Paulo. São Paulo: CETESB, 2009.

CONAMA. Conselho Nacional do Meio Ambiente. Resolução n. 357, de 17 de março de 2005. Dispõe sobre a classificação dos corpos de água e diretrizes ambientais para o seu enquadramento, bem como estabelece as condições e padrões de lançamento de efluentes, e dá outras providências. Brasília: DOU, 2005.

KEMERICH, P. D. C.; MARTINS, S. R.; KOBIYAMA, M.; SANTI, A. L.; FLORES, C. E. B.; BORBA, W. F.; FERNANDES, G. D.; CHERUBIN, M. R.. Qualidade da água oriunda do escoamento superficial simulado em bacia hidrográfica. Ciência e Natura, v.35, n.2, 2013. DOI: http://dx.doi.org/10.5902/2179460X12568

KOCH, F. F.; KAUFFMANN, C.; BICA, J. B.; ADAMI, F. S.; STEVENS, J. F.; ECKHARD, C. L.; MARMITT, L. G.; OLIVEIRA E. C.. Análise de água superficial para consumo humano em um município do Rio Grande do Sul. Revista Caderno Pedagógico, v.14, n.1, 2017. DOI: http://dx.doi.org/10.22410/issn.19830882.v14i1a2017.1398

MAPA. Ministério Da Agricultura, Pecuária e Abastecimento. Instrução Normativa n. 62, de 29 de dezembro de 2011. Brasília: DOU, 2011.

MARTINS, J. A.; DALLACORT, R.; INOUE, M. H.; GALVANIN, E. A. S.; MAGNANI, E. B. Z.; OLIVEIRA, K. C.. Caracterização do regime pluviométrico no arco das nascentes do Rio Paraguai. Revista Brasileira de Meteorologia, v.26, n.4, p.639-647, 2011. DOI: https://doi.org/10.1590/S010277862011000400013

QUEIROZ, T. M.; OLIVEIRA, L. C. P.. Qualidade da água em comunidades quilombolas do Vão Grande, município de Barra do Bugres/MT. Engenharia Sanitária e Ambiental, v.23, n.1, p.173-180, 2018. DOI:

http://doi.org/10.1590/s1413-41522018166375

SANTOS, R. S.; MORH, T.. Saúde e qualidade da água: análises microbiológicas e físico-químicas em águas subterrâneas. Revista Contexto \& Saúde, v.13, n.24-25, p.46-53, 2013. DOI: http://doi.org/10.21527/21767114.2013.24-25.46-53 
SCURACCHIO, P. A.; FARACHE FILHO, A.. Qualidade da água utilizada para consumo em escolas e creches no município de São Carlos/SP. Alimentos e Nutrição Araraquara, v.22, n.4, p.641-647, 2012

SILVA, D. R. R.; MACIEL, M. O. S.; MARTA, B. B. F.; BRONHARO, T. M.; MICHELIN, A. F.. Qualidade da água em escolas públicas municipais: análise microbiológica e teor de nitrato em Araçatuba, estado de São Paulo, Brasil. Rev. Inst. Adolfo Lutz, v.77, p.1740, 2018.

SILVEIRA, J. T.; CAPALONGA, R.; OLIVEIRA, A. B. A.; CARDOSO, M. R. I.. Avaliação de parâmetros microbiológicos de potabilidade em amostras de água provenientes de escolas públicas. Rev. Inst. Adolfo Lutz, v.70, n.3, 2011.
SOTO, F. R. M.; FONSECA, Y. S. K.; RISSETO, M. R.; AZEVEDO, S. S.; ARINI, M. L. B.; RIBAS, M. A.; MOURA, C. R. V.; MARCHETTE, D. S.. Monitoramento da qualidade da água de poços rasos de escolas públicas da zona rural do município de Ibiúna/SP: parâmetros microbiológicos, físico-químicos e fatores de risco ambiental. Rev. Inst. Adolfo Lutz, v.65, n.2, p.106-111, 2006

UNEMAT. Universidade do Estado de Mato Grosso. Faculdade Indígena Intercultural: Histórico. Cuiabá: Portal UNEMAT, 2019.

WHO. World Health Organization. Guidelines for drinkingwater quality. 4 ed. WHO, 2011.

A CBPC - Companhia Brasileira de Produção Científica (CNPJ: 11.221.422/0001-03) detém os direitos materiais desta publicação. Os direitos referem-se à publicação do trabalho em qualquer parte do mundo, incluindo os direitos às renovações, expansões e disseminações da contribuição, bem como outros direitos subsidiários. Todos os trabalhos publicados eletronicamente poderão posteriormente ser publicados em coletâneas impressas sob coordenação da Sustenere Publishing, da Companhia Brasileira de Produção Científica e seus parceiros autorizados. Os (as) autores (as) preservam os direitos autorais, mas não têm permissão para a publicação da contribuição em outro meio, impresso ou digital, em português ou em tradução. 